\title{
Can surgical need in patients with Naja atra (Taiwan or Chinese cobra) envenomation be predicted in the emergency department?
}

\author{
HY Su, MJ Wang, YH Li, CN Tang, MJ Tsai *
}

\section{A B S T R A C T}

Objectives: To investigate the clinical predictors and the aetiologies for surgery in patients with Naja atra (Taiwan or Chinese cobra) envenomation.

Methods: This case series was conducted in the only tertiary care centre in eastern Taiwan. Patients who presented to the emergency department with Naja atra bite between January 2008 and September 2014 were included. Clinical information was collected and compared between surgical and non-surgical patients.

Results: A total of 28 patients with Naja atra envenomation presented to the emergency department during the study period. Of these, $60.7 \%$ $(\mathrm{n}=17)$ required surgery. Necrotising fasciitis $(76.5 \%)$ was the main finding in surgery. Comparisons between surgical and non-surgical patients showed skin ecchymosis (odds ratio $=34.36 ; 95 \%$ confidence interval, 2.20-536.08; $\mathrm{P}=0.012$ ) and a high total dose of antivenin ( $\geq 6$ vials; odds ratio $=14.59$; $95 \%$ confidence interval, $1.10-192.72 ; \mathrm{P}=0.042)$ to be the most significant predictors of surgery. The rate of bacterial isolation from the surgical wound was 88.2\%. Morganella morganii (76.5\%), Enterococcus faecalis (58.8\%), and Bacteroides fragilis (29.4\%) were the most common pathogens involved. Bacterial susceptibility testing indicated that combined broad-

This article was published on 12 Aug 2016 at www.hkmj.org. spectrum antibiotics were needed to cover mixed aerobic and anaerobic bacterial infection.
Conclusions: Patients with Naja atra envenomation who present with skin ecchymosis or the need for a high dose of antivenin may require early surgical assessment. Combined broad-spectrum antibiotics are mandatory.

\section{Hong Kong Med J 2016;22:435-44}

DOI: $10.12809 / \mathrm{hkmj} 154739$

\author{
$1 \mathrm{HY} \mathrm{Su}, \mathrm{MD}$ \\ ${ }^{2}$ MJ Wang, PhD \\ ${ }^{3} \mathrm{YH} \mathrm{Li}, \mathrm{PhD}$ \\ ${ }^{4} \mathrm{CN}$ Tang, $\mathrm{MD}$ \\ ${ }^{5}$ MJ Tsai ${ }^{*}, \mathrm{MD}, \mathrm{PhD}$
}

Department of Emergency Medicine, E-Da Hospital and I-Shou University, Kaohsiung, Taiwan; Department of Emergency Medicine, Buddhist Tzu Chi General Hospital, Hualien, Taiwan

2 Department of Medical Research, Buddhist Tzu Chi General Hospital, Hualien, Taiwan

${ }^{3}$ Department of Public Health, Tzu Chi University, Hualien, Taiwan

${ }^{4}$ Department of Family Medicine, Buddhist Tzu Chi General Hospital, Hualien, Taiwan

${ }^{5}$ Department of Emergency Medicine, Ditmanson Medical Foundation Chiayi Christian Hospital, Chiayi, Taiwan; Department of Sports Management, Chia Nan University of Pharmacy and Science, Tainan, Taiwan

* Corresponding author: tshi33@gmail.com

An earlier version of this paper was presented at the 7 th Asian Conference on Emergency Medicine held in Tokyo, Japan on 23-25 October 2013.

New knowledge added by this study

- Among the six major venomous snakebites in Taiwan, Naja atra envenomation most commonly leads to surgical intervention.

- Ecchymosis on the bite wound may be a good indicator for surgical need in $N$ atra envenomation.

- Adequate antibiotic treatment may play an important role in the early management of $N$ atra envenomation.

Implications for clinical practice or policy

- Surgical debridement and broad-spectrum antibiotic treatment are suggested in patients with $N$ atra envenomation who develop ecchymosis. Surgery is more likely when high-dose antivenin has been used.

\section{Introduction}

Snakebites are an important public health and wilderness medical issue in Taiwan. Because of the warm and humid climate in Taiwan, there are more than 40 terrestrial snake species, of which 15 are venomous. Six of the venomous species are of high clinical importance, including Protobothrops mucrosquamatus (Taiwan Habu), Trimeresurus stejnegeri (Taiwan bamboo viper), Naja atra (Taiwan or Chinese cobra), Bungarus multicinctus (banded krait), Deinagkistrodon acutus (hundred pacer), and Daboia russelii siamensis (Russell's viper). ${ }^{1,2}$

Naja atra belongs to the Elapidae family, and in addition to Taiwan, it inhabits southern China, Hong Kong, northern Laos, and northern Vietnam. ${ }^{3}$ Cobra venom contains a mixture of components, 


\section{能否在急症室預測被舟山眼鏡蛇（台灣眼鏡蛇或 中華眼鏡蛇）咬傷的病人是否需要做手術？ \\ 蘇泓源、王美人、李奕慧、鄭秦妮、蔡銘仁}

目的：探討被舟山眼鏡蛇（又稱台灣眼鏡蛇或中華眼鏡蛇 ）咬傷而需 要做手術的病人的臨床預測因素和病因。

方法：本病例系列在台灣東部唯一一間三級醫療中心內進行。研究對 象包括於 2008 年 1 月至 2014 年9月期間被舟山眼鏡蛇咬傷並送院的病 人。比較進行手術與無進行手術病人的臨床資料。

結果：研究期間被舟山眼鏡蛇咬傷而入診急症室共有 28 例。其中 $60.7 \%$ （17例）須接受手術治療。病例中有 $76.5 \%$ 屬壞死性筋膜炎。 將手術和非手術患者進行比較, 發現皮膚瘀斑（比值比=34.36；95\% 置信區間2.20-536.08；P=0.012）和使用高劑量抗蛇毒血清（6小瓶 或以上；比值比 $=14.59 ； 95 \%$ 置信區間 $1.10-192.72 ； \mathrm{P}=0.042 ）$ 是進 行手術的顯著預測因素。病人傷口的細菌分離率為 $88.2 \%$ 。摩氏摩根 (76.5\%) 、粪腸球菌（58.8\%）和脆弱擬桿菌（29.4\%）是最常見的 病原體。細菌藥敏測試顯示須結合廣譜抗生素以治療需氧菌和厭氧菌 的混合細菌感染。

結論：被舟山眼鏡蛇咬傷的病人如有皮膚瘀斑和使用高劑量抗蛇毒血 清, 或須盡早評估是否進行手術。治療必須結合廣譜抗生素使用。

including cardiotoxin, cobrotoxin, haemotoxin, and phospholipase A2. ${ }^{4}$ Patients envenomed by a cobra experience varying degrees of neurotoxicity and cytotoxicity depending upon the proportions of the venom components. Due to evolution and geographical variations, different cobra species cause distinct clinical effects. For example, Naja philippinensis (northern Philippine cobra) causes a purely neurotoxic effect without local cytotoxicity. ${ }^{5}$ In contrast, $N$ atra envenomation is associated with more cytotoxic effects. ${ }^{3,6,7}$ Although an equine-derived bivalent $F(a b) 2$ antivenin has been produced by the Centers for Disease Control, ROC (Taiwan) to neutralise the venom of $N$ atra, the surgical intervention rate remains high. ${ }^{1,8}$ The main objective of this study was to investigate the clinical presentations and predictors for surgery in patients with $N$ atra envenomation. Due to high wound infection rates, the isolated bacteria from surgical wounds and the antimicrobial susceptibility were also analysed.

\section{Methods}

\section{Study design and patient population}

The Buddhist Tzu Chi General Hospital is the only tertiary care centre in eastern Taiwan. There are 1000 beds and the emergency department (ED) has more than 55000 patient visits per year. This hospital is also the toxicant, drug information, and antidote control centre for eastern Taiwan. A retrospective study was conducted to analyse data from patients admitted to the ED with $N$ atra envenomation between 1 January 2008 and 30 September 2014.

\section{Data collection, processing, and categorisation}

A medical assistant was responsible for collecting the medical records of patients admitted with snakebite during the study period by using the computerised chart system and International Classification of Diseases, 9th Revision, Clinical Modification codes 989.5, E905.0, E905.9, E906.2, and E906.5. Two physicians (the first and fifth authors) independently reviewed the charts and categorised these patients as having venomous or non-venomous snakebites based on the patient's presentation with or without toxic effects. For venomous snakebites, classification of the snake species was based on the identification of the snake brought in by the patient or identification by the patient from a picture. All the included patients had a compatible presentation and consistent antivenin use as recorded in the patient chart. Patients who were initially recognised as having venomous snakebites but did not receive antivenin treatment were excluded from the study because of the high probability of a dry bite or misidentification of the snake species. Patients with a toxic presentation who could not identify the snake species or who received more than one type of antivenin were recorded as having an unknown poisonous snakebite.

Here we only report patients who were bitten by $N$ atra. To identify the early clinical predictors of surgery, we categorised the patients into surgical and non-surgical groups. All surgical interventions were performed after surgical consultation in the ED or after admission when patients presented with progressive signs suggesting tissue necrosis, necrotising fasciitis, or suspected compartment syndrome. The final diagnoses of necrotising fasciitis and compartment syndrome were made according to surgical pathological findings and intracompartmental pressure measurement, respectively. The surgical procedures included debridement, fasciotomy, skin graft, and digit or limb amputation. The potential clinical predictors of surgery in $N$ atra envenomation included the patient's age, gender, season of snakebite, comorbidities, details of envenomation, site of snakebite, initial vital signs on arriving at the ED, clinical presentation, laboratory data, treatment, timing of initial antivenin therapy, and total dose of antivenin.

For the laboratory analyses, the initial data obtained in the ED were collected, including haematology, biochemistry, and coagulation profiles. In regard to clinical presentation, the local signs and symptoms, local complications, and systemic manifestations and complications were classified. Local signs and symptoms included swelling, ecchymosis, necrosis, numbness, and bulla formation. Local complications included necrotising 
fasciitis and suspected compartment syndrome. collected data was resolved through discussion with Systemic manifestations and complications included the third physician on the research team. The study neurological symptoms, including ptosis, blurred protocol was approved by the institutional review vision, drooling, and paralysis of facial, limb, or board of the Buddhist Tzu Chi General Hospital respiratory muscles; leukocytosis, defined as a white (IRB102-38). All patient records and information blood cell count of $>11.0 \times 10^{9} / \mathrm{L}$; thrombocytopenia, were anonymised and de-identified prior to analysis. defined as a platelet count of $<150 \times 10^{3} / \mathrm{mm}^{3} ;$ prothrombin time (PT) prolongation, defined as PT of $>11.6$ seconds; activated partial thromboplastin time (aPTT) prolongation, defined as aPTT of $>34.9$ seconds (prolonged PT and aPTT were defined according to our clinical laboratory reference range); fibrinogen consumption, defined as a fibrinogen level of $<1.8 \mathrm{~g} / \mathrm{L}$; elevated D-dimer level, defined as a D-dimer level of $>500 \mu \mathrm{g} / \mathrm{L}$; acute renal impairment, defined as a creatinine level of $>123.8 \mu \mathrm{mol} / \mathrm{L}^{9}$; and rhabdomyolysis, defined as a creatine kinase level of $>1000 \mathrm{U} / \mathrm{L} .{ }^{10}$ Two physicians reviewed the charts of the enrolled patients and rechecked the accuracy of the data collection. If the patient's initial vital signs were not measured or laboratory tests were not performed in the ED, this was recorded as a missing value in the database. Any discrepancy regarding the

\section{Statistical analyses}

To identify significant early clinical presentation and laboratory data associated with surgery in patients with $N$ atra envenomation, the Student's $t$ test or the Mann-Whitney $U$ test for continuous variables and Chi squared test for categorical variables were used to perform univariate analysis. A P value of $<0.05$ was considered statistically significant, and all statistical tests were two-tailed. For multivariate analysis, the categorical variables with a $\mathrm{P}$ value of $<0.05$ in the initial univariate analysis were selected and entered into a logistic regression forward stepwise Wald test to calculate the odds ratios (ORs). The Statistical Package for the Social Sciences (Windows version 12.0; SPSS Inc, Chicago [IL], US) was used to perform the statistical analyses.

TABLE I. Clinical characteristics of the 17 surgical patients with Naja atra envenomation

\begin{tabular}{|c|c|c|c|c|c|c|c|c|c|c|c|c|c|c|c|c|}
\hline \multirow{2}{*}{$\begin{array}{l}\text { Pa- } \\
\text { tient } \\
\text { No. }\end{array}$} & \multirow{2}{*}{$\begin{array}{c}\text { Age } \\
\text { (years) }\end{array}$} & \multirow[t]{2}{*}{ Sex } & \multirow[t]{2}{*}{ Site of bite } & \multirow{2}{*}{$\begin{array}{c}\text { Preoperative } \\
\text { clinical } \\
\text { features }\end{array}$} & \multirow{2}{*}{$\begin{array}{l}\text { Time to } \\
\text { arrive } \\
\text { hospital } \\
\text { (hours)* }\end{array}$} & \multicolumn{2}{|c|}{$\begin{array}{l}\text { Final operative } \\
\text { diagnosis }\end{array}$} & \multicolumn{4}{|c|}{$\begin{array}{l}\text { Received procedure and } \\
\text { frequency }\end{array}$} & \multirow{2}{*}{$\begin{array}{c}\text { Anti- } \\
\text { venin } \\
\text { dosage } \\
\text { (vials) }\end{array}$} & \multirow{2}{*}{$\begin{array}{c}\text { Time to } \\
\text { receive } \\
\text { surgery† } \\
\text { (days) }\end{array}$} & \multirow{2}{*}{$\begin{array}{c}\text { Size of } \\
\text { debride- } \\
\text { ment } \\
\text { wound } \\
\left(\mathrm{cm}^{2}\right)\end{array}$} & \multirow{2}{*}{$\begin{array}{l}\text { Inten- } \\
\text { sive } \\
\text { care }\end{array}$} & \multirow{2}{*}{$\begin{array}{c}\text { Duration } \\
\text { of } \\
\text { hospital- } \\
\text { isation } \\
\text { (days) }\end{array}$} \\
\hline & & & & & & $\begin{array}{c}\text { Simple } \\
\text { skin or } \\
\text { subcu- } \\
\text { taneous } \\
\text { necrosis }\end{array}$ & $\begin{array}{l}\text { Necro- } \\
\text { tising } \\
\text { fasciitis }\end{array}$ & $\begin{array}{l}\text { Fascio- } \\
\text { tomy }\end{array}$ & $\begin{array}{l}\text { Debride- } \\
\text { ment }\end{array}$ & $\begin{array}{l}\text { Skin } \\
\text { graft }\end{array}$ & $\begin{array}{l}\text { Ampu- } \\
\text { tation }\end{array}$ & & & & & \\
\hline 1 & 24 & $\mathrm{~F}$ & Right leg & $E, S$ & 0.5 & - & + & 1 & 1 & 1 & 0 & 6 & 5 & $15 \times 8$ & - & 26 \\
\hline 2 & 26 & $M$ & Right hand & $\mathrm{C}, \mathrm{E}, \mathrm{S}, \mathrm{N}, \mathrm{NC}$ & 1 & - & + & 1 & 2 & 0 & 0 & 7 & 7 & $15 \times 2$ & - & 20 \\
\hline 3 & 33 & $\mathrm{~F}$ & Right leg & $E, S$ & 1 & - & + & 1 & 2 & 3 & 0 & 6 & 9 & $12 \times 10$ & - & 40 \\
\hline 4 & 34 & $M$ & Left hand & $\mathrm{B}, \mathrm{E}, \mathrm{S}, \mathrm{NC}$ & 1 & - & + & 1 & 1 & 0 & 1 & 18 & 7 & $3 \times 2$ & - & 24 \\
\hline 5 & 42 & $M$ & Left hand & $\mathrm{E}, \mathrm{S}, \mathrm{N}, \mathrm{NC}$ & 0.5 & - & + & 1 & 6 & 2 & 0 & 11 & 4 & $10 \times 3.5$ & - & 23 \\
\hline 6 & 43 & $M$ & Left hand & $\mathrm{E}, \mathrm{S}, \mathrm{NC}$ & 1 & - & + & 1 & 4 & 0 & 0 & 5 & 2 & $7 \times 2$ & - & 30 \\
\hline 7 & 45 & $M$ & Left hand & $\mathrm{E}, \mathrm{S}, \mathrm{N}, \mathrm{NC}$ & 1 & - & + & 1 & 2 & 1 & 0 & 22 & 1 & $15 \times 10$ & - & 30 \\
\hline 8 & 45 & $\mathrm{~F}$ & Right leg & $E, S, N$ & 1 & - & + & 1 & 2 & 1 & 0 & 13 & 1 & $17 \times 3$ & - & 38 \\
\hline 9 & 59 & $M$ & Left foot & $\mathrm{C}, \mathrm{E}, \mathrm{S}, \mathrm{NC}$ & 6 & - & + & 2 & 2 & 1 & 0 & 10 & 2 & $15 \times 6$ & - & 33 \\
\hline 10 & 60 & $M$ & Right hand & $\mathrm{B}, \mathrm{E}, \mathrm{S}, \mathrm{NC}$ & 1 & - & + & 1 & 1 & 1 & 1 & 10 & 11 & $20 \times 6$ & + & 37 \\
\hline 11 & 64 & M & Left hand & $\mathrm{B}, \mathrm{E}, \mathrm{S}, \mathrm{N}$ & 1 & + & - & 0 & 3 & 1 & 0 & 12 & 3 & $2 \times 2$ & - & 15 \\
\hline 12 & 67 & $M$ & Right hand & $\mathrm{B}, \mathrm{S}, \mathrm{N}, \mathrm{NC}$ & 1 & + & - & 0 & 2 & 0 & 0 & 7 & 14 & $2 \times 2$ & - & 15 \\
\hline 13 & 70 & $\mathrm{~F}$ & Left hand & $S$ & 1 & + & - & 0 & 2 & 1 & 0 & 8 & 1.5 & $1.5 \times 1$ & - & 15 \\
\hline 14 & 70 & $M$ & Right foot & $\mathrm{B}, \mathrm{E}, \mathrm{S}, \mathrm{N}, \mathrm{NC}$ & 4 & - & + & 1 & 1 & 0 & 0 & 8 & 3 & $10 \times 8$ & + & 16 \\
\hline 15 & 72 & $\mathrm{~F}$ & Left leg & $\mathrm{B}, \mathrm{E}, \mathrm{S}, \mathrm{N}, \mathrm{NC}$ & 0.5 & - & + & 1 & 2 & 1 & 0 & 4 & 5 & $23 \times 6$ & - & 41 \\
\hline 16 & 77 & $\mathrm{~F}$ & Left leg & $B, E, S$ & 1 & - & + & 1 & 1 & 1 & 0 & 6 & 14 & $10 \times 3$ & - & 45 \\
\hline 17 & 79 & $M$ & Left leg & $\mathrm{S}$ & 0.5 & + & - & 0 & 2 & 0 & 0 & 4 & 4 & $1 \times 0.8$ & - & 19 \\
\hline
\end{tabular}

Abbreviations: $B=$ bulla formation; $C=$ compartment sign; $E=$ ecchymosis; $F=$ female; $M=$ male; $N=$ numbness; $N C=$ necrosis; $S=$ swelling

* The time to arrive at our hospital after the bite

+ The time of initial presentation to the day of surgery

₹ Size of debridement wound was based on the final surgical report which indicated the wound size after receiving the repeated debridement 


\section{Results}

\section{Epidemiology and surgical intervention rate} for snake envenomation

Between 1 January 2008 and 30 September 2014, a total of 245 patients with venomous snakebites were recorded. Among these, 64 (26.1\%) patients had $P$ mucrosquamatus envenomation, 56 (22.9\%) had $T$ stejnegeri envenomation, 28 (11.4\%) had $N$ atra envenomation, five (2.0\%) had $B$ multicinctus envenomation, six (2.4\%) had D acutus envenomation, seven $(2.9 \%)$ had $D r$ siamensis envenomation, and 79 (32.2\%) had unknown poisonous snake envenomation.

The snakebites associated with the highest surgical intervention rates were $N$ atra (60.7\%), followed by D acutus (33.3\%), and P mucrosquamatus $(12.5 \%)$.

\section{Characteristics and clinical status of patients} with Naja atra envenomation

Of the 28 patients with a $N$ atra bite, $20(71.4 \%)$

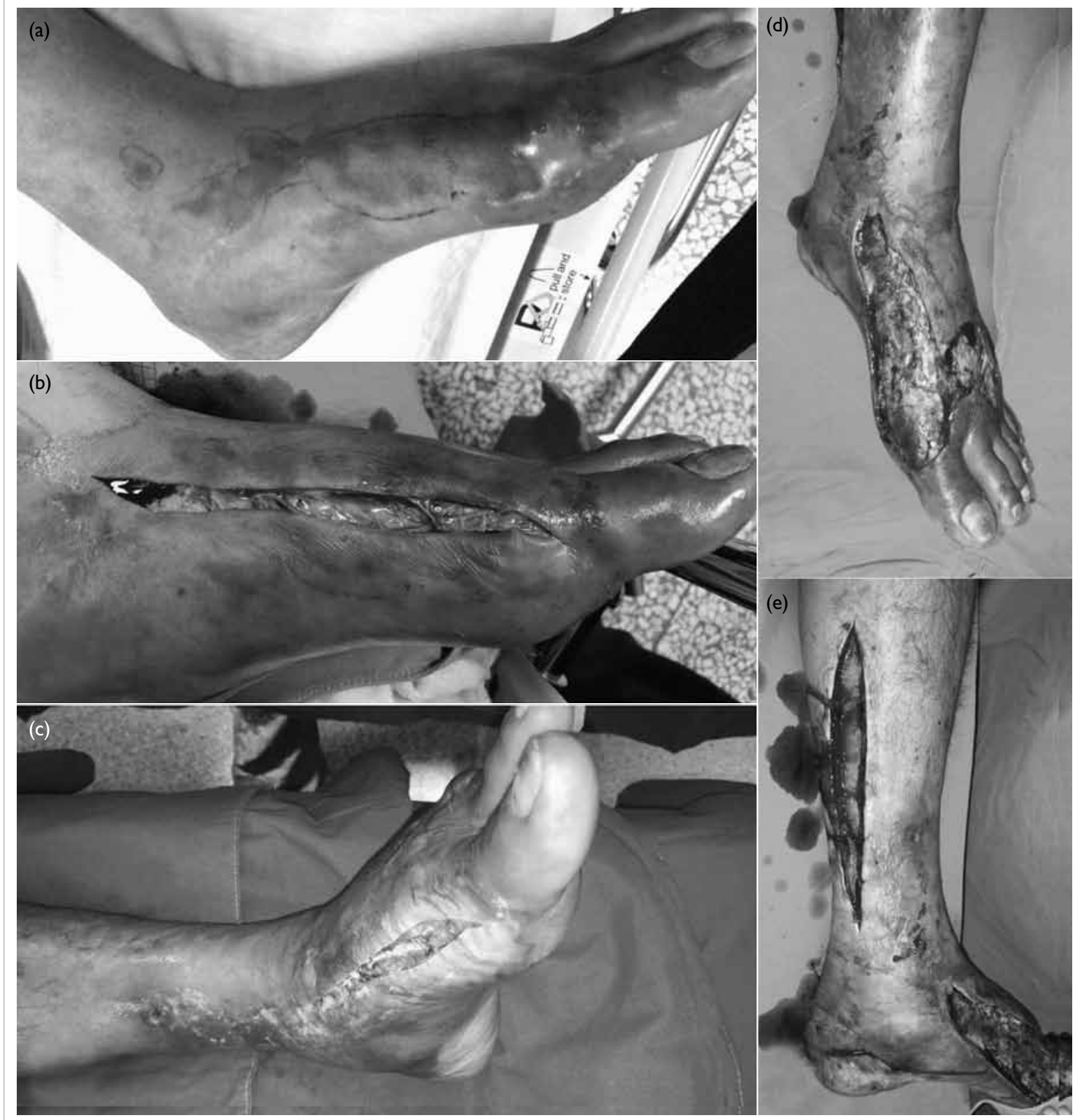

FIG. Patient No. 9 in Table I

A 59-year-old man bitten by Naja atra on his left foot visited our hospital 6 hours after the snakebite. (a) Despite the use of 10 vials of antivenin, progressive ecchymosis and necrosis on the bite wound developed later. (b) Fasciotomy and debridement were done on the second day of patient visit. (c) Progressive wound necrosis and necrotising fasciitis of the leg developed 5 days later. ( $d$ and e) He underwent second surgical debridement of the foot and fasciotomy of the leg 
TABLE 2. Clinical and laboratory characteristics of 28 patients with Naja atra envenomation

\begin{tabular}{|c|c|c|c|}
\hline Characteristic & Non-surgical $(n=11)^{\star}$ & Surgical $(n=17)^{*}$ & P value \\
\hline Age (years) & $50.3 \pm 14.9$ & $53.5 \pm 18.1$ & 0.624 \\
\hline Body temperature $\left({ }^{\circ} \mathrm{C}\right)$ & $36.0(36.0-36.3)[n=6]$ & $36.0(36.0-37.0)[n=9]$ & 0.528 \\
\hline Heart rate (beats/min) & $90.6 \pm 15.8$ & $95.4 \pm 16.5(n=16)$ & 0.454 \\
\hline Respiratory rate (breaths/min) & $18.0(16.0-18.0)[n=7]$ & $20.0(20.0-21.0)[n=5]$ & 0.015 \\
\hline \multicolumn{4}{|l|}{ Blood pressure (mm Hg) } \\
\hline Systolic & $151.5 \pm 33.0$ & $147.0 \pm 24.7(n=16)$ & 0.691 \\
\hline Diastolic & $95.1 \pm 18.7$ & $91.6 \pm 20.1(n=16)$ & 0.655 \\
\hline Time to initiation of antivenin (hours) & $1.0(0.5-2.0)$ & $1.0(1.0-1.0)$ & 0.596 \\
\hline Total dose of antivenin (No. of vials) & $3.8 \pm 2.4$ & $9.2 \pm 4.9$ & 0.002 \\
\hline \multicolumn{4}{|l|}{ ED laboratory data } \\
\hline WBC (x 109 /L) & $8.2 \pm 2.4(n=10)$ & $11.0 \pm 3.7$ & 0.043 \\
\hline $\mathrm{Hb}(\mathrm{g} / \mathrm{L})$ & $14.2 \pm 1.5(n=10)$ & $13.0 \pm 2.1$ & 0.112 \\
\hline $\operatorname{PLT}\left(\times 10^{9} / \mathrm{L}\right)$ & $217.2 \pm 55.5(n=10)$ & $250.0 \pm 99.6$ & 0.350 \\
\hline PT (secs) & $10.5 \pm 0.8(n=8)$ & $10.8 \pm 1.8(n=15)$ & 0.591 \\
\hline aPTT (secs) & $27.0 \pm 1.3(n=8)$ & $27.5 \pm 4.5(n=15)$ & 0.784 \\
\hline AST (U/L) & $51.6 \pm 61.5(n=10)$ & $149.4 \pm 418.6(n=15)$ & 0.433 \\
\hline $\mathrm{ALT}(\mathrm{U} / \mathrm{L})$ & $37.8 \pm 34.0(n=10)$ & $29.7 \pm 13.8$ & 0.494 \\
\hline BUN (mmol/L) & $5.4 \pm 2.5(n=10)$ & $6.6 \pm 5.5$ & 0.578 \\
\hline $\mathrm{CRE}(\mu \mathrm{mol} / \mathrm{L})$ & $79.6 \pm 26.5(n=10)$ & $123.8 \pm 106.1$ & 0.254 \\
\hline CK (U/L) & $326.0(250.0-402.0)[n=2]$ & $211.0(71.5-25$ 810.0) [n=5] & 0.548 \\
\hline Fibrinogen & $255.1(174.5-328.6)[n=3]$ & $341.1(285.5-534.9)[n=9]$ & 0.175 \\
\hline D-dimer & $314.0(235.5-348.6)[n=3]$ & $1654.5(501.1-2293.2)[n=9]$ & 0.432 \\
\hline
\end{tabular}

Abbreviations: ALT = alanine aminotransferase; aPTT = activated partial thromboplastin time; AST = aspartate aminotransferase; BUN = blood urea nitrogen; $C K=$ creatine kinase; $C R E=$ creatinine; $E D=$ emergency department; Hb = haemoglobin;

$\mathrm{PLT}=$ platelet count; $\mathrm{PT}=$ prothrombin time; $\mathrm{WBC}=$ white blood cell count

* Data are shown as mean \pm standard deviation, or median (interquartile range)

were male. The mean ( \pm standard deviation) age of patients was $52.3 \pm 3.2$ years. Of the patients, 22 (78.6\%) were bitten in the summer or fall; $17(60.7 \%)$ were bitten on an upper limb; and 17 (60.7\%) with $N$ atra envenomation received surgical treatment. These patients had a significantly longer duration of hospitalisation than non-surgical patients (27.5 \pm 10.2 days vs $2.7 \pm 3.1$ days; $\mathrm{P}<0.001)$. The main operative diagnosis was necrotising fasciitis $(n=13$, $76.5 \%$ ) with confirmation by histopathology. The clinical characteristics of the 17 surgical patients are shown in Table 1. The mean duration from the time of initial presentation to the day of surgery was 5.5 \pm 4.3 days. All 13 patients with necrotising fasciitis underwent emergency fasciotomy and debridement, and two required limb or digit amputation. The other four surgical patients without necrotising fasciitis only received local debridement with or without skin graft due to local tissue necrosis. Therefore, a smaller surgical wound and a shorter duration of hospitalisation were observed for these patients (Table 1). Nearly all surgical patients presented with local swelling and ecchymosis on the bite wound. Only one non-surgical patient presented with ecchymosis on a finger and was discharged from the ED 1 day later after four vials of antivenin were administered. The Figure shows the initial ecchymosis and necrosis of a N atra bite wound, the development of extensive tissue necrosis, and the postoperative wounds of a surgical patient (patient No. 9 in Table 1).

\section{Demographic and clinical characteristics associated with surgical treatment in patients with Naja atra envenomation}

The demographic and clinical characteristics were compared between the surgical and non-surgical patients with $N$ atra envenomation (Tables 2 and 3 ). Overall, the surgical patients received significantly higher doses of antivenin $(9.2 \pm 4.9$ vials vs $3.8 \pm$ 2.4 vials; $\mathrm{P}=0.002)$ and had significantly higher white blood cell counts $\left(11.0 \pm 3.7 \times 10^{9} / \mathrm{L}\right.$ vs 8.2 $\left.\pm 2.4 \times 10^{9} / \mathrm{L} ; \mathrm{P}=0.043\right)$. A higher respiratory rate was also evident in surgical patients (median [interquartile range]: 20 [20-21] vs 18 [16-18] breaths/min; $\mathrm{P}=0.015$ ), but the incidence of missing data in both groups for this factor was high (Table 
TABLE 3. Demographics, and clinical and laboratory characteristics of 28 patients with Naja atra envenomation

\begin{tabular}{|c|c|c|c|}
\hline \multirow[t]{2}{*}{ Characteristic } & \multicolumn{2}{|c|}{ No. $(\%)$ of patients } & \multirow[t]{2}{*}{$P$ value } \\
\hline & Non-surgical $(n=11)$ & Surgical $(n=17)$ & \\
\hline Age-groups (years) & & & 0.435 \\
\hline$\geq 60$ & $3(27.3)$ & $8(47.1)$ & \\
\hline$<60$ & $8(72.7)$ & $9(52.9)$ & \\
\hline Gender & & & 0.419 \\
\hline Male & $9(81.8)$ & $11(64.7)$ & \\
\hline Female & $2(18.2)$ & $6(35.3)$ & \\
\hline Season & & & 0.355 \\
\hline Summer and fall & $10(90.9)$ & $12(70.6)$ & \\
\hline Winter and spring & $1(9.1)$ & $5(29.4)$ & \\
\hline Site of snakebite & & & 0.435 \\
\hline Upper limb & $8(72.7)$ & $9(52.9)$ & \\
\hline Lower limb & $3(27.3)$ & $8(47.1)$ & \\
\hline Co-morbidity with diabetes & & & 1.000 \\
\hline Yes & $1(9.1)$ & $2(11.8)$ & \\
\hline No & $10(90.9)$ & $15(88.2)$ & \\
\hline Allergy to antivenin & & & 1.000 \\
\hline Yes & 0 & 0 & \\
\hline No & $11(100)$ & $17(100)$ & \\
\hline High dose of total antivenin use ( $\geq 6$ vials) & & & 0.001 \\
\hline Yes & $2(18.2)$ & $14(82.4)$ & \\
\hline No & $9(81.8)$ & $3(17.6)$ & \\
\hline \multicolumn{4}{|l|}{ Local signs and symptoms } \\
\hline Swelling & & & 0.05 \\
\hline Yes & $8(72.7)$ & $17(100)$ & \\
\hline No & $3(27.3)$ & 0 & \\
\hline Ecchymosis & & & $<0.001$ \\
\hline Yes & $1(9.1)$ & $14(82.4)$ & \\
\hline No & $10(90.9)$ & $3(17.6)$ & \\
\hline Necrosis & & & 0.002 \\
\hline Yes & 0 & $10(58.8)$ & \\
\hline No & $11(100)$ & $7(41.2)$ & \\
\hline Numbness & & & 1.000 \\
\hline Yes & $5(45.5)$ & $8(47.1)$ & \\
\hline No & $6(54.5)$ & $9(52.9)$ & \\
\hline Bulla formation & & & 0.023 \\
\hline Yes & 0 & $7(41.2)$ & \\
\hline No & $11(100)$ & $10(58.8)$ & \\
\hline \multicolumn{4}{|l|}{ Local complications } \\
\hline Suspected compartment syndrome & & & 0.505 \\
\hline Yes & 0 & $2(11.8)$ & \\
\hline No & $11(100)$ & $15(88.2)$ & \\
\hline Necrotising fasciitis & & & $<0.001$ \\
\hline Yes & 0 & $13(76.5)$ & \\
\hline No & $11(100)$ & $4(23.5)$ & \\
\hline
\end{tabular}

Abbreviations: $\mathrm{PPTT}=$ activated partial thromboplastin time; $\mathrm{CK}=$ creatine kinase; $\mathrm{CRE}=$ creatinine; $\mathrm{PLT}=$ platelet count; $\mathrm{PT}=$ prothrombin time; WBC = white blood cell count 
TABLE 3. (cont'd)

\begin{tabular}{|c|c|c|c|}
\hline \multirow[t]{2}{*}{ Characteristic } & \multicolumn{2}{|c|}{ No. (\%) of patients } & \multirow[t]{2}{*}{$P$ value } \\
\hline & Non-surgical $(n=11)$ & Surgical $(n=17)$ & \\
\hline \multicolumn{4}{|l|}{ Systemic manifestations and complications } \\
\hline Neurological symptoms & & & 1.000 \\
\hline Yes & 0 & 0 & \\
\hline No & $11(100)$ & $17(100)$ & \\
\hline Leukocytosis (WBC $\left.>11.0 \times 10^{9} / \mathrm{L}\right)$ & & & 0.190 \\
\hline Yes & $1(10.0)$ & $7(41.2)$ & \\
\hline No & $9(90.0)$ & $10(58.8)$ & \\
\hline Thrombocytopenia (PLT <150 x $10^{3} / \mathrm{mm}^{3}$ ) & & & 0.613 \\
\hline Yes & $2(20.0)$ & $2(11.8)$ & \\
\hline No & $8(80.0)$ & $15(88.2)$ & \\
\hline aPTT prolongation (>34.9 secs) & & & 1.000 \\
\hline Yes & 0 & $1(6.3)$ & \\
\hline No & $8(100)$ & $15(93.8)$ & \\
\hline PT prolongation (>11.6 secs) & & & 1.000 \\
\hline Yes & 0 & $1(6.3)$ & \\
\hline No & $8(100)$ & $15(93.8)$ & \\
\hline Fibrinogen consumption $(<1.8 \mathrm{~g} / \mathrm{L})$ & & & 0.214 \\
\hline Yes & $1(33.3)$ & 0 & \\
\hline No & $2(66.7)$ & $11(100)$ & \\
\hline Elevated initial D-dimer (>500 $\mu \mathrm{g} / \mathrm{L})$ & & & 0.192 \\
\hline Yes & 0 & $7(63.6)$ & \\
\hline No & $3(100)$ & $4(36.4)$ & \\
\hline Acute renal impairment (CRE $>123.8 \mu \mathrm{mol} / \mathrm{L})$ & & & 0.236 \\
\hline Yes & $3(30.0)$ & $10(58.8)$ & \\
\hline No & $7(70.0)$ & $7(41.2)$ & \\
\hline Rhabdomyolysis (CK >1000 U/L) & & & 1.000 \\
\hline Yes & 0 & $1(16.7)$ & \\
\hline No & $2(100)$ & $5(83.3)$ & \\
\hline
\end{tabular}

2). A significantly higher proportion of surgical patients received six or more vials of antivenin in total compared with non-surgical patients $(82.4 \%$ vs $18.2 \% ; \mathrm{P}=0.001$ ) [Table 3]. For local signs, symptoms and complications, a significantly higher proportion of surgical patients presented with local swelling (100\% vs $72.7 \% ; \mathrm{P}=0.05)$, ecchymosis $(82.4 \%$ vs $9.1 \%$; $\mathrm{P}<0.001)$, necrosis $(58.8 \%$ vs $0 \%, \mathrm{P}=0.002)$, bulla formation ( $41.2 \%$ vs $0 \% ; \mathrm{P}=0.023)$, and necrotising fasciitis ( $76.5 \%$ vs $0 \% ; \mathrm{P}<0.001)$ [Table 3]. Age, season and site of snakebite, co-morbidity with diabetes, allergy to antivenin, and other systemic manifestations were not found to be significantly different between surgical and non-surgical patients. None of the patients with $N$ atra envenomation presented with neurological symptoms. One patient with a small area of ecchymosis on the bite wound of his left hand did not receive surgical intervention, because the condition of the local wound improved and healed after administration of four vials of antivenin and intravenous antibiotics.

\section{Independent predictors of surgery in patients with Naja atra envenomation}

To determine clinical predictors of surgery, a multivariate logistic regression analysis was conducted for the significant variables derived from the univariate analysis. Necrotising fasciitis was not included in the multivariate analysis because it was a surgical finding and not an early sign that could be identified in the ED. The results showed that local ecchymosis $(\mathrm{OR}=34.36 ; 95 \%$ confidence interval [CI], 2.20-536.08; $\mathrm{P}=0.012$ ) and a high total dose of antivenin ( $\geq 6$ vials; $\mathrm{OR}=14.59 ; 95 \% \mathrm{CI}, 1.10-192.72$; $\mathrm{P}=0.042$ ) were the most significant clinical predictors of surgery in patients with $N$ atra envenomation. 


\section{Bacterial isolates identified from the snakebite wounds of surgical patients with Naja atra envenomation, and bacterial susceptibility to common antibiotics}

To analyse the cause of necrotising fasciitis in surgical patients, the bacterial isolates identified from snakebite wounds were further analysed in surgical patients. The positive culture rate was $88.2 \%(n=15)$. More than one type of bacteria were isolated from the snakebite wound in $14(82.4 \%)$ surgical patients. The isolated pathogens included aerobic Gram-positive and Gram-negative bacteria, as well as anaerobic bacteria. The most commonly identified pathogen was Morganella morganii (76.5\%), followed by Enterococcus faecalis (58.8\%) and Bacteroides fragilis (29.4\%) [Table 4].

The susceptibility of the bacteria to common antibiotics was analysed (Table 5). All Grampositive bacteria were susceptible to vancomycin and teicoplanin. All Gram-negative bacteria were susceptible to cefotaxime and amikacin. Cefmetazole, gentamicin, levofloxacin, and trimethoprim/ sulfamethoxazole were also effective against the isolated Gram-negative bacteria. Nearly all anaerobic bacteria were susceptible to clindamycin and metronidazole (Table 5).
TABLE 4. Bacterial isolates from snakebite wounds of surgical patients*

\begin{tabular}{lc}
\hline Pathogen & $\begin{array}{c}\text { No. (\%) of patients } \\
(\mathbf{n}=\mathbf{1 7})\end{array}$ \\
\hline Aerobic Gram-positive bacteria & $10(58.8)$ \\
\hline Enterococcus faecalis & $2(11.8)$ \\
Coagulase-negative staphylococci & \\
\hline Aerobic Gram-negative bacteria & $13(76.5)$ \\
\hline Morganella morganii & $3(17.6)$ \\
\hline Proteus vulgaris & $2(11.8)$ \\
\hline Proteus mirabilis & $2(11.8)$ \\
\hline Escherichia coli & $1(5.9)$ \\
\hline Aeromonas hydrophila & $1(5.9)$ \\
\hline Shewanella putrefaciens & $1(5.9)$ \\
\hline Serratia marcescens & \\
Anaerobic bacteria & $5(29.4)$ \\
\hline Bacteroides fragilis & $1(5.9)$ \\
\hline Bacteroides eggerthii &
\end{tabular}

* More than one kind of bacteria were isolated from snakebite wound in 14 patients who received surgery with Naja atra envenomation

TABLE 5. Susceptibility of bacteria isolated from snakebite wounds to common antibiotics* $†$

\begin{tabular}{|c|c|c|c|c|c|c|c|c|c|c|c|c|}
\hline \multirow[t]{3}{*}{ Pathogens } & \multicolumn{12}{|c|}{ Antibiotics } \\
\hline & \multicolumn{6}{|c|}{ Penicillin \& penicillin combination groups } & \multicolumn{6}{|c|}{ Cephalosporins } \\
\hline & PCN & Amp & $\mathrm{A} / \mathrm{C}$ & A/S & $\mathbf{P} / \mathbf{T}$ & T/C & Cef & Cefu & Cefm & Cefo & Ceft & Cefe \\
\hline \multicolumn{13}{|l|}{ Aerobic Gram-positive bacteria } \\
\hline Enterococcus groups & $10(10)$ & $10(10)$ & & & & & & & & & & \\
\hline Coagulase-negative staphylococci & $0(2)$ & & & & & & $0(2)$ & & & & & \\
\hline \multicolumn{13}{|l|}{ Aerobic Gram-negative bacteria } \\
\hline Morganella morganii & & $1(13)$ & $2(8)$ & $1(4)$ & $9(9)$ & $4(4)$ & $1(13)$ & $2(7)$ & $11(11)$ & $13(13)$ & $9(9)$ & $5(5)$ \\
\hline Proteus vulgaris & & $0(3)$ & $2(2)$ & & $2(2)$ & $1(1)$ & $0(3)$ & $2(2)$ & $2(2)$ & $3(3)$ & $2(2)$ & $1(1)$ \\
\hline Proteus mirabilis & & $0(2)$ & $1(2)$ & & & & $0(2)$ & $0(2)$ & $2(2)$ & $2(2)$ & & \\
\hline Escherichia coli & & $0(2)$ & $1(2)$ & & $1(1)$ & $1(1)$ & $1(2)$ & $1(2)$ & $2(2)$ & $2(2)$ & $1(1)$ & \\
\hline Aeromonas hydrophila & & $0(1)$ & & $0(1)$ & $1(1)$ & & $0(1)$ & & $0(1)$ & $1(1)$ & $1(1)$ & $1(1)$ \\
\hline Shewanella putrefaciens & & $0(1)$ & $1(1)$ & & $1(1)$ & $1(1)$ & $0(1)$ & $0(1)$ & $1(1)$ & $1(1)$ & $1(1)$ & \\
\hline Serratia marcescens & & $0(1)$ & & $0(1)$ & $1(1)$ & & $0(1)$ & & $1(1)$ & $1(1)$ & $1(1)$ & $1(1)$ \\
\hline \multicolumn{13}{|l|}{ Anaerobic bacteria } \\
\hline Bacteroides fragilis & $0(5)$ & & & $0(4)$ & & & & & $2(5)$ & & & \\
\hline Bacteroides eggerthii & $0(1)$ & & & $1(1)$ & & & & & $1(1)$ & & & \\
\hline
\end{tabular}

Abbreviations: $\mathrm{A} / \mathrm{C}=$ amoxicillin/clavulanic acid; $\mathrm{A} / \mathrm{S}=$ ampicillin/sulbactam; Ami = amikacin; Amp = ampicillin; Cef = cefazolin; Cefe = cefepime; Cefm = cefmetazole; Cefo = cefotaxime; Ceft = ceftazidime; Cefu = cefuroxime; Cip = ciprofloxacin; Clin = clindamycin; Ert = ertapenem; Gen = gentamicin; Imi = imipenem; Levo = levofloxacin; Mero = meropenem; Metro = metronidazole; $\mathrm{P} / \mathrm{T}=$ piperacillin/tazobactam; $\mathrm{PCN}=$ penicillin; $\mathrm{T} / \mathrm{C}=\mathrm{ticarcillin} / \mathrm{clavulanate}$; $\mathrm{T} / \mathrm{S}=$ trimethoprim/sulfamethoxazole; Tei = teicoplanin; $\mathrm{Van}=$ vancomycin

* Values are shown as No. of patients with susceptibility to specific antibiotics (total No. of patients with the specific antibiotic sensitivity test)

+ If the same type of bacterial culture was found in different samples from one patient, it was defined as the same clone in the table 


\section{Discussion}

In our study, skin change of ecchymosis on the bite wound was a good clinical predictor of surgery for $N$ atra envenomation. The majority of $N$ atra venom is cytotoxic, not haemorrhagic. The cardiotoxin and phospholipase A2 in $N$ atra venom are direct cytotoxic polypeptides and cause degradation of cell membranes. They induce cell death by activating calcium-dependent proteases, and inhibit mitochondrial respiration. Hyaluronidase in $N$ atra venom destroys interstitial constituents and precipitates the spreading of venom. ${ }^{11}$ A histopathological study of $N$ atra bite wounds demonstrated thrombotic and fibrinoid deposits in superficial and deep dermal vessels, and leukocytoclastic vasculitis. ${ }^{12}$ Hence, both the cytotoxic and ischaemic effects of $N$ atra venom may lead to blood extravasation from the destroyed subcutaneous vessels or capillaries and result in the characteristic ecchymosis on the bite wound. This finding may be a potentially important clinical sign of irreversible subcutaneous tissue necrosis due to development of tissue ischaemia. ${ }^{3}$ If management at this stage is inadequate, tissue destruction may progress to involve the fascia rapidly and extensively with ultimate development of necrotising fasciitis. ${ }^{13}$ In our patients, extensive tissue destruction beyond the original bite site was evident once necrotising fasciitis developed. Further study is required to verify whether early surgical intervention can prevent the development of necrotising fasciitis, reduce the size of surgical wound, or shorten the length of hospital stay. Nonetheless, surgical assessment may be needed in patients with $N$ atra bite who present with local ecchymosis on the bite wound.

Traditionally, immediate injection of antivenin to neutralise $N$ atra venom was the only efficient management. ${ }^{14}$ A study using an enzyme-linked immunosorbent assay to detect the amount of $N$ atra venom revealed that two to eight vials of antivenin are sufficient to eliminate systemic circulating venom if presentation is early. ${ }^{6}$ The efficacy of systemically administrated antivenin to diminish local tissue destruction is still controversial, however, and needs further study. ${ }^{3}$ In an animal study, the cytotoxic venom of $N$ atra was shown to bind with high affinity to tissues leading to high levels of local tissue destruction. ${ }^{15}$ This finding may explain the difficulties associated with neutralisation of local venom toxicity, especially in cases of delayed presentation. Thus, the adequate dose of antivenin for preventing advanced tissue destruction remains unknown. In our study, nearly all patients presented within 1 hour following envenoming. Intravenous injection of antivenin was administered as soon as clinically possible following identification of cobra envenoming. Interestingly, the use of higher doses of antivenin in patients with $N$ atra envenomation did not decrease surgical rates even in cases of

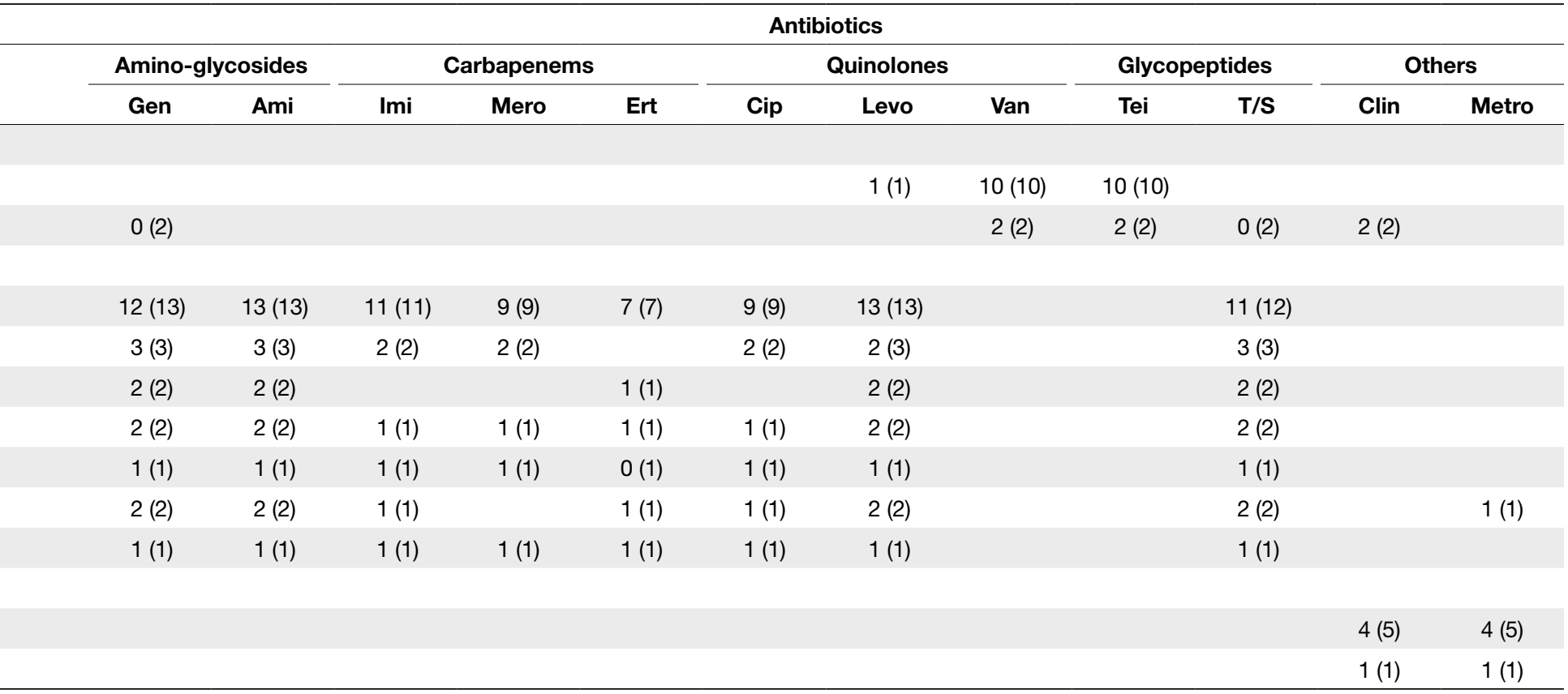


early presentation. More than half of the patients underwent surgery and the majority were diagnosed with necrotising fasciitis. Surgical intervention appears to be crucial for the management of $N$ atra envenomation. Hence, the identification of clinical predictors of surgical need and sufficient evidence to support surgeons' decisions to carry out early surgical intervention are important issues in $N$ atra management.

High bacterial isolation rates and the growth of mixed spectrums of bacteria from bite wounds indicate bacterial infection (which may be another cause of necrotising fasciitis in $N$ atra envenomation), bacterial colonisation, or both. Morganella morganii and Enterococcus species were the most common pathogens cultured from $N$ atra bite wounds in this study. This finding is consistent with the bacterial cultures taken from oral swabs of $N$ atra in Hong Kong. ${ }^{16}$ Similar results were also described in a previous study in western Taiwan. ${ }^{17}$ Hence, the use of adequate antibiotics is important in $N$ atra envenomation management. In accordance with the results of our tests of the antibiotic susceptibility of the isolated bacteria, treatment with glycopeptide antibiotics (vancomycin or teicoplanin) combined with a third-generation cephalosporin (cefotaxime) with or without anti-anaerobic antibiotics (clindamycin or metronidazole) is recommended.

\section{Limitations}

There are several limitations in our study. First, this was a retrospective chart review comparative study. Non-uniform description of symptoms and signs documented by different providers may have influenced the validity of the statistics. Second, the small sample size may limit the statistical power in the multivariate analysis. Third, there are no definitive guidelines for the management of venomous snakebites in Taiwan, and various treatment strategies were employed; this may have influenced the final outcome. A large-scale prospective study is warranted to verify the risk factors we have identified to provide more accurate data for early risk stratification, treatment, and management of these patients.

\section{Conclusions}

Of the six common venomous snakes in eastern Taiwan, bites by $N$ atra most frequently lead to surgical intervention. Severe tissue necrosis and necrotising fasciitis were the main findings during surgery. Patients who present with ecchymosis on the bite wound or who require higher doses of antivenin may have a higher probability of surgical intervention. In addition to early and adequate antivenin treatment, combined broad-spectrum antibiotics and surgical intervention may be needed in the management of $N$ atra snakebites.

\section{Acknowledgement}

This work was supported by Buddhist Tzu Chi General Hospital Grants TCRD103-53 (to the first author).

\section{Declaration}

All authors have disclosed no conflicts of interest.

\section{References}

1. Liau MY, Huang RJ. Toxoids and antivenoms of venomous snakes in Taiwan. Toxin Rev 1997;16:163-75.

2. Hung DZ. Taiwan's venomous snakebite: epidemiological, evolution and geographic differences. Trans R Soc Trop Med Hyg 2004;98:96-101.

3. Wong OF, Lam TS, Fung HT, Choy CH. Five-year experience with Chinese cobra (Naja atra)-related injuries in two acute hospitals in Hong Kong. Hong Kong Med J 2010;16:36-43.

4. Li S, Wang J, Zhang X, et al. Proteomic characterization of two snake venoms: Naja naja atra and Agkistrodon halys. Biochem J 2004;384:119-27.

5. Watt G, Padre L, Tuazon L, Theakston RD, Laughlin L. Bites by the Philippine cobra (Naja naja philippinensis): prominent neurotoxicity with minimal local signs. Am J Trop Med Hyg 1988;39:306-11.

6. Hung DZ, Liau MY, Lin-Shiau SY. The clinical significance of venom detection in patients of cobra snakebite. Toxicon 2003;41:409-15.

7. Wang W, Chen QF, Yin RX, et al. Clinical features and treatment experience: A review of 292 Chinese cobra snakebites. Environ Toxicol Pharmacol 2014;37:648-55.

8. Huang LW, Wang JD, Huang JA, Hu SY, Wang LM, Tsan YT. Wound infections secondary to snakebite in central Taiwan. J Venom Anim Toxins Incl Trop Dis 2012;18:2726.

9. Hung DZ, Wu ML, Deng JF, Lin-Shiau SY. Russell's viper snakebite in Taiwan: differences from other Asian countries. Toxicon 2002;40:1291-8.

10. Chen YW, Chen MH, Chen YC, et al. Differences in clinical profiles of patients with Protobothrops mucrosquamatus and Viridovipera stejnegeri envenoming in Taiwan. Am J Trop Med Hyg 2009;80:28-32.

11. Harris JB. Myotoxic phospholipases A2 and the regeneration of skeletal muscles. Toxicon 2003;42:933-45.

12. Pongprasit P, Mitrakul C, Noppakun N. Histopathology and microbiological study of cobra bite wounds. J Med Assoc Thai 1988;71:475-80.

13. Gozal D, Ziser A, Shupak A, Ariel A, Melamed Y. Necrotizing fasciitis. Arch Surg 1986;121:233-5.

14. Russell FE. Snake venom immunology: historical and practical considerations. Toxin Rev 1988;7:1-82.

15. Guo MP, Wang QC, Liu GF. Pharmacokinetics of cytotoxin from Chinese cobra (Naja naja atra) venom. Toxicon 1993;31:339-43.

16. Lam KK, Crow P, Ng KH, et al. A cross-sectional survey of snake oral bacterial flora from Hong Kong, SAR, China. Emerg Med J 2011;28:107-14.

17. Chen CM, Wu KG, Chen CJ, Wang CM. Bacterial infection in association with snakebite: a 10-year experience in a northern Taiwan medical center. J Microbiol Immunol Infect 2011;44:456-60. 